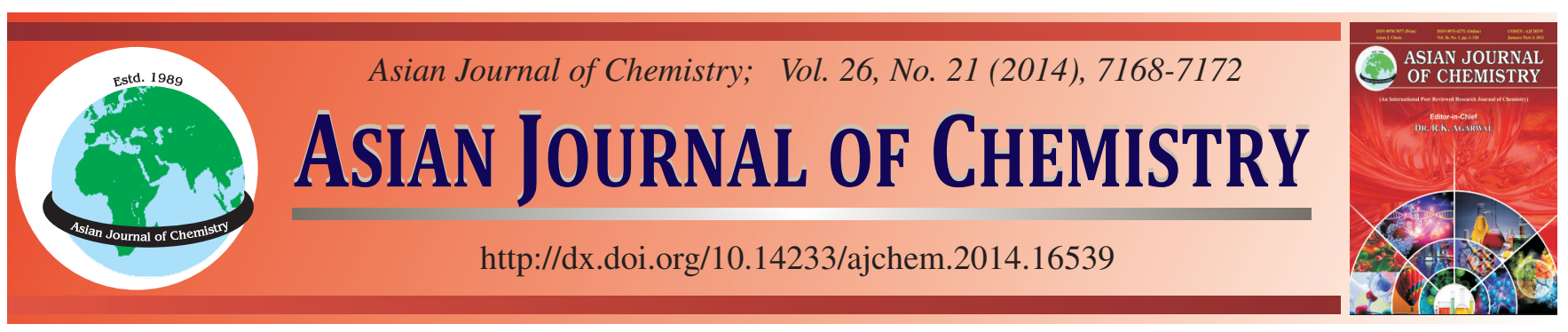

\title{
Chemical Composition and Antifungal Activity of Essential Oils of Eupatorium catarium and Eupatorium odoratum from China
}

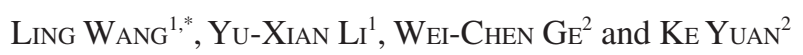

${ }^{1}$ College of Pharmacy, Henan University of Traditional Chinese Medicine, Zhengzhou 450008, P.R. China

${ }^{2}$ Zhejiang Agriculture and Forestry University, Lin'an 311300, P.R. China

*Corresponding author: E-mail: wangling1961@163.com

\begin{abstract}
Essential oils of two compositae species, including Eupatorium catarium and Eupatorium odoratum, harvested in Hainan province, extracted by hydrodistillation, were analyzed by GC and GC/MS. The antifungal activity of the oils against 8 phytopathogenic fungi (Fusarium graminearum, Botrytis cinerea, Exerohilum turcicum, Mucor, Sclerotinia sclerotiorum, Rhizoctonia solani AG1-IA, Rhizoctonia solani Kühn, Fusarium graminearum Schwabe.) was tested by determining minimum inhibitory concentrations (MIC) using the microdilution method. The two oils exhibited potent antifungal activities.
\end{abstract}

Keywords: Eupatorium catarium, Eupatorium odoratum, Essential oils, Antifungal activity.

\section{INTRODUCTION}

In last few years, there has been an increase in the use of naturally derived compounds, such as essential oils, that justifies the increment observed in oils production ${ }^{1}$. Aromatic plants are frequently used in traditional medicine. Essential oils and volatile constituents extracted from them are widely used as antioxidants or antidiabetic agents and for prevention and treatment of different human diseases, such as cancer, cardiovascular diseases, including atherosclerosis, thrombosis, bacterial, fungi and viral infections ${ }^{2}$.

E. catarium and E. odoratum, which are originated from Central America, South America, Africa and the tropical areas of Asia, are perennial herbal or half-shrub plants, belonging to Eupatorium of the compositae family. From 1865, these two plants were introduced as ornamental plants to such countries as the United States, Britain and Australia, etc. In the twenties of the 20th century, they were introduced to Thailand as the aromatic plants and in 1934, they were first found in Yunnan Province, China. At present, they have spread to many different region in China, such tropical or sub-tropical areas as Hainan Island, Guangdong, Taiwan, Guangxi, Yunnan, Guizhou, Hongkong and Macao, etc. Nowadays, they are widely distributed along the roadsides and mountain slopes in the tropical and sub-tropical areas of the world in China, they are mainly seen in the areas of Guangdong, Hainan, Guangxi and Yunnan. E. catarium and E. odoratum have the medical effects of eliminating blood stagnation and swelling, detoxi- fication and hemostasis, mainly used in curing abnormal menstruation, falling injuries and swelling pains, ulcers and boils and even in curing nameless boils and traumatic bleeding.

This research takes water-vapor distillation method to extract the volatile oil in E. catarium and E. odoratum and uses gas chromatograph-mass spectrometer technology to separate and determine the chemical components in the volatile oil. Meanwhile it adopts the method of peak-area normalization to determine the percentage of the chemical components in the volatile oil. The research also use the Oxford-cup method, it assesses the antimicrobial activity of the volatile oil by eight species of fungi. The result of the experiments can provide reference for further research on the chemical components of volatile oil in the E. catarium and E. odoratum of aromatic plants and antimicrobial activity as well as for the exploration and utilization of it.

\section{EXPERIMENTAL}

The fresh leaves of E. catarium and E. odoratum were collected on Hainan Province, China in Aug. 2011, Botanical identification was carried out by medicinal plant taxonomic Prof. Shi-Man Huang of Hainan University. Voucher specimens of the samples have been deposited with Plant laboratory of Zhejiang A \& F University.

Essential oils extraction: Dried leaves of E. catarium and E. odoratum were subjected to hydrodistillation for 5 and $4 \mathrm{~h}$, respectively, using a clevenger-type apparatus. The 
obtained oils were dried (anhydrous $\mathrm{Na}_{2} \mathrm{SO}_{4}$ ) and stored in sealed flasks at $4{ }^{\circ} \mathrm{C}$.

The oils were analyzed by GC and GC/MS by using a DB-5 column as previously described (20). The main components are reported in Table-1, the chromatogram of the total ion current of the 2 volatile chemical components (Fig. 1 and Table-1).

Antifungal bioassay: The test phytopathogenic fungi used in this study were Fusarium graminearum, Botrytis cinerea, Exerohilum turcicum, Mucor, Sclerotinia sclerotiorum,

TABLE-1

ANALYTICAL RESULTS OF CHEMICAL CONSTITUENTS OF THE ESSENTIAL OIL FROM THE TWO SAMPLES

\begin{tabular}{|c|c|c|c|c|c|c|}
\hline No. & Name of components & m.f. & $\begin{array}{c}\mathrm{RT} \\
(\mathrm{min})\end{array}$ & RI & $\begin{array}{l}\text { Area } \% \text { of } \\
\text { E. catarium }\end{array}$ & $\begin{array}{l}\text { Area } \% \text { of } \\
\text { E. odoratum }\end{array}$ \\
\hline 1 & Eucalyptol & $\mathrm{C}_{10} \mathrm{H}_{18} \mathrm{O}$ & 7.84 & 1207.927 & 0.57 & ---- \\
\hline 2 & 3,4-Diethenyl-3-methyl-cyclohexene & $\mathrm{C}_{11} \mathrm{H}_{18}$ & 9.74 & 1321.788 & 0.66 & 1.01 \\
\hline 3 & (Z)-3-hexen-1-ol & $\mathrm{C}_{6} \mathrm{H}_{12} \mathrm{O}$ & 10.79 & 1380.447 & 0.84 & ---- \\
\hline 4 & $\alpha$-Cubebene & $\mathrm{C}_{15} \mathrm{H}_{24}$ & 12.20 & 1454.639 & 0.84 & 0.87 \\
\hline 5 & $\begin{array}{l}\text { 4-Ethenyl-4-methyl-3-(1-methylethenyl)-1-(1-methylethyl)-(3R-trans)- } \\
\text { cyclohexene }\end{array}$ & $\mathrm{C}_{15} \mathrm{H}_{24}$ & 12.40 & 1464.948 & 0.51 & 0.57 \\
\hline 6 & Copaene & $\mathrm{C}_{15} \mathrm{H}_{24}$ & 12.87 & 1489.175 & 0.51 & ---- \\
\hline 7 & Ylangene & $\mathrm{C}_{15} \mathrm{H}_{24}$ & 12.94 & 1492.784 & ---- & 5.35 \\
\hline 8 & $\begin{array}{l}\text { Ecahydro-3 } \alpha \text {-methyl-6-methylene-1-(1-methylethyl)-[1S- }(1 \alpha, 3 \alpha \alpha, 3 \alpha \beta, 6 \alpha \alpha, 6 \alpha \beta)] \\
\text {-cyclobuta[1,2,3,4]dicyclopentene }\end{array}$ & $\mathrm{C}_{15} \mathrm{H}_{24}$ & 13.41 & 1516.256 & 1.32 & 0.76 \\
\hline 9 & (2,6,6-Trimethylcyclohex-1-enylmethanesulfonyl)benzene & $\mathrm{C}_{16} \mathrm{H}_{22} \mathrm{O}_{2} \mathrm{~S}$ & 13.61 & 1526.108 & 0.51 & ---- \\
\hline 10 & $\begin{array}{l}\text { Octahydro-7-methyl-3-methylene-4-(1-methylethyl)-[3 } \alpha \mathrm{S} \text { - } \\
\left.\left(3 \alpha \alpha, 3 \alpha \beta, 4 \alpha, 7 \alpha, 7 \alpha \mathrm{S}^{*}\right)\right]-1 H \text {-cyclopenta[1,3]cyclopropa[1,2]benzene }\end{array}$ & $\mathrm{C}_{15} \mathrm{H}_{24}$ & 13.77 & 1533.990 & 0.53 & 0.55 \\
\hline 11 & 3,7-Dimethyl-1,6-octadien-3-ol & $\mathrm{C}_{10} \mathrm{H}_{18} \mathrm{O}$ & 13.87 & 1538.916 & ---- & 0.68 \\
\hline 12 & Isocaryophillene & $\mathrm{C}_{12} \mathrm{H}_{18}$ & 14.54 & 1571.921 & ---- & 2.01 \\
\hline 13 & 1-Ethenyl-1-methyl-2,4-bis(1-methylethenyl)-[1S-(1 $\alpha, 2 \alpha, 4 \alpha)]$-cyclohexane, & $\mathrm{C}_{15} \mathrm{H}_{24}$ & 14.90 & 1589.655 & 1.80 & 2.67 \\
\hline 14 & Caryophyllene & $\mathrm{C}_{15} \mathrm{H}_{24}$ & 15.15 & 1601.914 & 15.22 & 15.59 \\
\hline 15 & trans- $\alpha-$-Santalol & $\mathrm{C}_{15} \mathrm{H}_{24} \mathrm{O}$ & 15.76 & 1631.100 & 0.60 & ---- \\
\hline 16 & $\begin{array}{l}\text { Decahydro-1,1,7-trimethyl-4-methylene-[1 } \alpha \mathrm{R}-(1 \alpha \alpha, 4 \alpha \alpha, 7 \alpha, 7 \alpha \alpha, 7 \alpha \beta)]-1 H \text { - } \\
\text { cycloprop[e]azulene }\end{array}$ & $\mathrm{C}_{15} \mathrm{H}_{24}$ & 15.98 & 1641.627 & 0.61 & ---- \\
\hline 17 & 3-Furanmethanol & $\mathrm{C}_{5} \mathrm{H}_{6} \mathrm{O}_{2}$ & 16.20 & 1652.153 & ---- & 0.68 \\
\hline 18 & 1,1,4,8-Tetramethyl-cis,cis,cis-4,7,10-cycloundecatriene & $\mathrm{C}_{15} \mathrm{H}_{24}$ & 16.52 & 1667.464 & 3.12 & 3.88 \\
\hline 19 & $\begin{array}{l}1,2,3,4,4 \alpha, 5,6,8 \alpha \text {-Octahydro-7-methyl-4-methylene-1-(1-methylethyl)-( } 1 \alpha, 4 \alpha \alpha, \\
8 \alpha \alpha) \text {-naphthalene }\end{array}$ & $\mathrm{C}_{15} \mathrm{H}_{24}$ & 16.88 & 1684.689 & 2.41 & 1.52 \\
\hline 20 & (+)- $\alpha$-Terpineol ( $p$-menth-1-en-8-ol) & $\mathrm{C}_{10} \mathrm{H}_{20} \mathrm{O}$ & 17.03 & 1691.866 & 0.75 & ---- \\
\hline 21 & Isoledene & $\mathrm{C}_{15} \mathrm{H}_{24}$ & 17.32 & 1705.769 & 8.19 & ---- \\
\hline 22 & $\begin{array}{l}1 \alpha, 2,3,4,4 \alpha, 5,6,7 \beta \text {-Octahydro-1,1,4,7-tetramethyl-[1 } \alpha \mathrm{R}-(1 \alpha \alpha, 4 \alpha, 4 \alpha \alpha, 7 \alpha \beta)]-1 H \text { - } \\
\text { cycloprop[e]azulene }\end{array}$ & $\mathrm{C}_{15} \mathrm{H}_{24}$ & 17.36 & 1707.692 & -- & 9.80 \\
\hline 23 & Germacrene D & $\mathrm{C}_{15} \mathrm{H}_{24}$ & 17.42 & 1710.577 & 8.48 & 4.50 \\
\hline 24 & 1,2,4 $\alpha, 5,6,8 \alpha$-Hexahydro-4,7-dimethyl-1-(1-methylethyl)-naphthalene & $\mathrm{C}_{15} \mathrm{H}_{24}$ & 17.61 & 1719.712 & ---- & 1.27 \\
\hline 25 & Elemene & $\mathrm{C}_{15} \mathrm{H}_{24}$ & 17.81 & 1729.327 & 1.23 & ---- \\
\hline 26 & $\begin{array}{l}1,2,4 \alpha, 5,8,8 \alpha \text {-Hexahydro-4,7-dimethyl-1-(1-methylethyl)-[1S-(1 } \alpha, 4 \alpha \alpha, 8 \alpha \alpha)] \text { - } \\
\text { naphthalene }\end{array}$ & $\mathrm{C}_{15} \mathrm{H}_{24}$ & 18.37 & 1756.250 & 0.96 & 7.19 \\
\hline 27 & Hexanoic acid & $\mathrm{C}_{6} \mathrm{H}_{12} \mathrm{O}_{2}$ & 18.94 & 1783.654 & 1.65 & ---- \\
\hline 28 & Thymol & $\mathrm{C}_{10} \mathrm{H}_{14} \mathrm{O}$ & 20.09 & 1839.706 & 0.65 & ---- \\
\hline 29 & Benzyl alcohol & $\mathrm{C}_{7} \mathrm{H}_{8} \mathrm{O}$ & 20.66 & 1867.647 & 1.70 & 0.85 \\
\hline 30 & Butylated hydroxytoluene & $\mathrm{C}_{15} \mathrm{H}_{24} \mathrm{O}$ & 21.38 & 1903.109 & 6.79 & ---- \\
\hline 31 & Cadala-1(10),3,8-triene & $\mathrm{C}_{15} \mathrm{H}_{22}$ & 21.44 & 1906.218 & ---- & 0.64 \\
\hline 32 & Caryophyllene oxide & $\mathrm{C}_{15} \mathrm{H}_{24} \mathrm{O}$ & 22.90 & 1981.865 & 7.49 & 6.25 \\
\hline 33 & 1,2-Dimethoxy-4-(2-propenyl)-benzene & $\mathrm{C}_{11} \mathrm{H}_{14} \mathrm{O}_{2}$ & 23.34 & 2005.732 & 0.98 & 7.93 \\
\hline 34 & $\begin{array}{l}\text { 1,5,5,8-Tetramethyl-[1R-(1R*,3E,7E,11R*)]-12-oxabicyclo[9.1.0]dodeca-3,7- } \\
\text { diene }\end{array}$ & $\mathrm{C}_{15} \mathrm{H}_{24} \mathrm{O}$ & 23.82 & 2036.306 & 0.63 & 0.54 \\
\hline 35 & Epiglobulol & $\mathrm{C}_{15} \mathrm{H}_{26} \mathrm{O}$ & 24.47 & 2077.707 & 0.56 & ---- \\
\hline 36 & trans-Longipinocarveol & $\mathrm{C}_{15} \mathrm{H}_{26} \mathrm{O}$ & 24.93 & 2110.377 & 0.52 & ---- \\
\hline 37 & (-)-Spathulenol & $\mathrm{C}_{15} \mathrm{H}_{24} \mathrm{O}$ & 25.09 & 2125.471 & 8.26 & 0.90 \\
\hline 38 & 9-Methyl-10-methylenetricyclo[4.2.1.1(2,5)]decan-9-ol & $\mathrm{C}_{12} \mathrm{H}_{18} \mathrm{O}$ & 25.21 & 2136.792 & ---- & 1.30 \\
\hline 39 & 2-Methoxy-3-(2-propenyl)-phenol & $\mathrm{C}_{10} \mathrm{H}_{12} \mathrm{O}_{2}$ & 25.59 & 2172.642 & 5.94 & 1.47 \\
\hline 40 & Selinene & $\mathrm{C}_{15} \mathrm{H}_{24}$ & 25.67 & 2180.187 & ---- & 0.62 \\
\hline 41 & $\tau$-Cadinol & $\mathrm{C}_{15} \mathrm{H}_{26} \mathrm{O}$ & 25.69 & 2182.075 & 2.15 & ---- \\
\hline 42 & 2-Methoxy-4-vinylphenol & $\mathrm{C}_{9} \mathrm{H}_{10} \mathrm{O}_{2}$ & 25.94 & 2184.345 & ---- & 0.77 \\
\hline 43 & 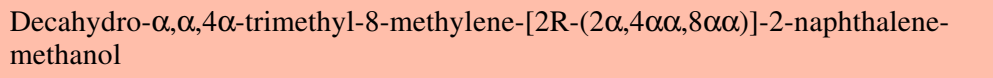 & $\mathrm{C}_{15} \mathrm{H}_{28} \mathrm{O}$ & 26.46 & 2228.070 & ---- & 2.62 \\
\hline 44 & $\alpha$-Cadinol & $\mathrm{C}_{15} \mathrm{H}_{26} \mathrm{O}$ & 26.47 & 2228.947 & 1.91 & ---- \\
\hline 45 & $(-)-$ Spathulenol & $\mathrm{C}_{15} \mathrm{H}_{24} \mathrm{O}$ & 26.72 & 2250.877 & 0.66 & ---- \\
\hline 46 & 3-(2-Hydroxyphenyl)-(E)-2-propenoic acid & $\mathrm{C}_{9} \mathrm{H}_{8} \mathrm{O}_{2}$ & 28.16 & 2386.275 & ---- & 2.18 \\
\hline 47 & $n$-Hexadecanoic acid & $\mathrm{C}_{16} \mathrm{H}_{32} \mathrm{O}_{2}$ & 35.19 & ---- & 1.65 & 1.91 \\
\hline
\end{tabular}




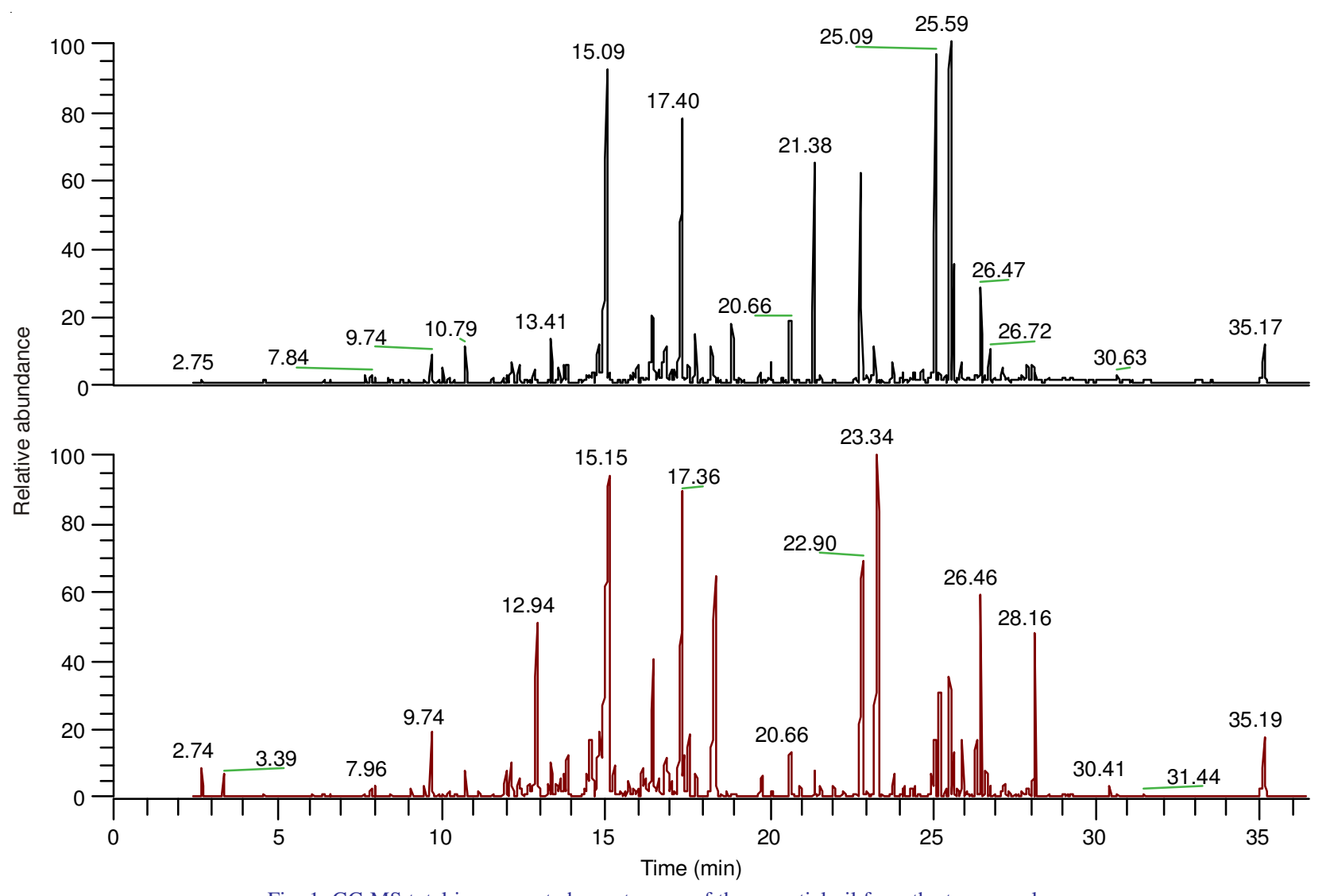

Fig. 1. GC-MS total ion current chromatogram of the essential oil from the two samples

Rhizoctonia solani AG1-IA, Rhizoctonia solani Kühn, Fusarium graminearum Schwabe. All the fungi were isolated from infected plant organs at the Zhejiang A \& F University.

Antifungal activity was assessed by the microbroth dilution method in 96-well culture plates using a potato dextrose (PD) medium. The serial doubling dilution of the essential oil and its major compound was prepared in dimethyl sulfoxide, with concentrations ranging from 0.195 to $25 \mu \mathrm{L} \mathrm{mL}^{-1}$. Final concentration of DMSO never exceeded $2 \%$. A commercial fungicide carbendazim (Aladdin chemistry Co. Ltd.) was used as positive control and the solution of equal concentration of DMSO was used as a negative control. The tested fungi were incubated in the PD medium for $18 \mathrm{~h}$ at $28 \pm 0.5^{\circ} \mathrm{C}$ at $150 \mathrm{rpm}$ and spores of different microorganism concentrations were diluted to approximately $1 \times 106 \mathrm{CFU}$ with PD medium. The test oils $(10 \mu \mathrm{L})$ were added to 96 -well microplates and $90 \mu \mathrm{L}$ of PD medium was added. Serial dilutions were made in the 96-well round-bottom sterile plates in triplicate in $50 \mu \mathrm{L}$ of PD medium and then $50 \mu \mathrm{L}$ of the fungal suspension was added. After incubation for $48 \mathrm{~h}$ at $28 \pm 0.5^{\circ} \mathrm{C}$, minimum inhibitory concentration (MIC) was taken as the lowest concentration of the test compounds in the wells of the 96-well plate in which no microbial growth could be observed.

\section{RESULTS AND DISCUSSION}

Chemical composition of essential oils: We identified 47 kinds of compounds in the volatile oil of 2 eupatorium plants (Table-1). Among these, 35 kinds of compounds are from E. catarium, accounting for $91.20 \%$ of the total peak area, while in E. odoratum, 30 are identified, accounting for $86.88 \%$. In the plants of the different species of the same family, the similarity of the volatile components is very high, but with different contents. The compounds with the highest contents in the 2 plants are both caryophyllene. The ingredient with relative high contents in the volatile oil of E. catarium is mainly caryophyllene $(15.22 \%)$, germacrene $\mathrm{D}(8.48 \%)$, (-)-spathulenol $(8.26 \%)$, isoledene $(8.19 \%)$, caryophyllene oxide (7.49 $\%)$, butylated hydroxytoluene $(6.79 \%), 2$-methoxy-3-(2propenyl)-phenol (5.94\%), 1,1,4,8-tetramethyl-cis,cis,cis4,7,10-cycloundecatriene $(3.12 \%)$. The ingredient with relative high contents in the volatile of E. odoratum is mainly caryophyllene $(15.59 \%), 1 \alpha, 2,3,4,4 \alpha, 5,6,7 \beta$-octahydro1,1,4,7-tetramethyl-[1 $\alpha \mathrm{R}-(1 \alpha \alpha, 4 \alpha, 4 \alpha \alpha, 7 \alpha \beta)]$-1H-cycloprop[e]azulene $(9.80 \%), 1,2$-dimethoxy-4-(2-propenyl)-benzene (7.93\%), 1,2,4 $\alpha, 5,8,8 \alpha$-hexahydro-4,7-dimethyl-1-(1-methylethyl)-[1S-(1 $\alpha, 4 \alpha \alpha, 8 \alpha \alpha)]$-naphthalene (7.19\%), caryophyllene oxide $(6.25 \%)$, ylangene $(5.35 \%)$, germacrene D $(4.50 \%)$, 1,1,4,8-tetramethyl-cis, cis,cis-4,7,10- cycloundecatriene (3.88 $\%)$. Compound 1: Caryophyllene, compound 2: $1 \alpha, 2,3,4,4 \alpha$, 5,6,7 $\beta$-Octahydro-1,1,4,7-tetramethyl-[1aR- $(1 \alpha \alpha, 4 \alpha, 4 \alpha \alpha$, $7 \alpha \beta)]-1 H$-cycloprop[e]azulene, compound 3: Germacrene D, compound 4: (-)-Spathulenol, compound 5: Isoledene, compound 6: Caryophyllene oxide, compound 7: Butylated hydroxytoluene, compound 8: 1,2-Dimethoxy-4-(2-propenyl)benzene, compound 9: 2-Methoxy-3-(2-propenyl)phenol, compound 10: Ylangene (Fig. 2).

The yield of oil from E. catarium was $2.6 \%$ (v/w) and was more higher than the another tested specie. GC/MS identified 35 compounds, representing $91.20 \%$ of the oil content. Caryophyllene was the main monoterpene hydrocarbon, with 


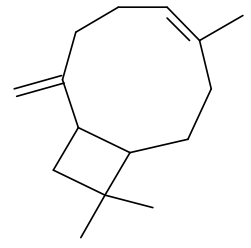

1

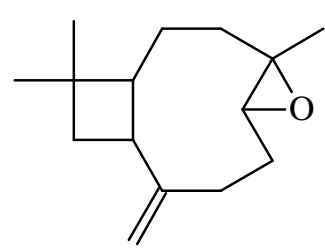

6

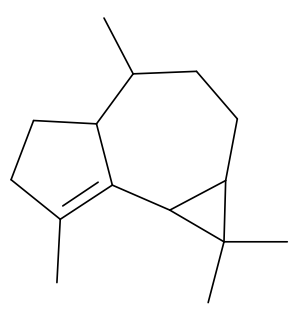

2

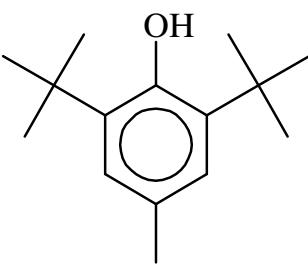

7<smiles>C=C1/C=C\C(C(C)C)CC/C(C)=C\CC1</smiles>

3<smiles>C=CCc1ccc(OC)c(OC)c1</smiles>

8

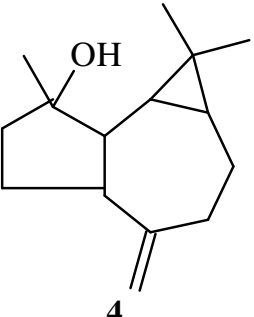<smiles>CC1CCC2C(C3=C1CCC3C)C2(C)C</smiles>

5<smiles>C=CCc1cccc(O)c1OC</smiles>

10

Fig. 2. Representative volatile compounds of essential oil from the E. catarium and E. odoratum

a content of $15.22 \%$. The (-)-spathulenol, germacrene D and isoledene contents were $8.26,8.48$ and $8.19 \%$, respectively. The content of caryophyllene oxide was $7.49 \%$. Our literature review found few reports on the chemical composition of E. catarium oil. Chang et al. ${ }^{1}$ found similar amounts of caryophyllene, significantly higher germacrene D and no (-)-spathulenol in wild E. catarium.

The oil yield for E. odoratum was $3.2 \%$ (v/w), with 30 compounds identified that represented $86.88 \%$ of the oil content. The main components were caryophyllene (15.59\%), $1 \alpha, 2,3,4,4 \alpha, 5,6,7 \beta$-octahydro-1,1,4,7-tetramethyl-[1 $\alpha \mathrm{R}$-( $1 \alpha$, $4 \alpha, 4 \alpha, 7 \beta)]$ - $1 H$-cycloprop[e]azulene $(9.80 \%), 1,2$-dimethoxy4-(2-propenyl)-benzene (7.93\%), 1, 2, 4 $\alpha, 5,8,8 \alpha$-hexahydro4,7-dimethyl-1-(1-methylethyl)-[1S-(1 $\alpha, 4 \alpha, 8 \alpha)]$-naphthalene $(7.19 \%)$ and caryophyllene oxide $(6.25 \%)$. A number of studies on essential oil content and constituents of E. catarium have been performed. Yuan et $a l^{2}{ }^{2}$ showed that supercritical carbon dioxide extraction (SFE) of the essential oil detected 65 compounds in the plant from cultivated sources, with 9methyl-10-methylene-tricyclo[4.2.1.1(2, 5)]decan-9-ol $(13.66 \%)$ and fumaric acid, ethyl 2-(2-methylenecyclopropyl) propyl ester $(5.02 \%)$ as the major constituents. It should also be mentioned that the contents of caryophyllene and caryophyllene oxide in the present study were much higher than those of Yuan et al. ${ }^{2}$. It was noteworthy that the compositions of the E. odoratum oil were in partial agreement with those reported by other authors by high content of caryophyllene ${ }^{3}$. Interestingly, the major constituents copaene and cadiene found by Lin et al. ${ }^{3}$ were not examined in our results. Moreover, the percentages of each constituent in the $C$. japonica leaf oils were similar to those found in previous studied by Ling et al. ${ }^{4}$. Thus, essential-oil-bearing plants usually show a variable chemical composition due to both intrinsic (sexual, seasonal, ontogenetic and genetic variations) and extrinsic (ecological and environmental aspects) factors.

Mono- and sesquiterpene hydrocarbons were the characteristic constituents of the two oils. There is an enormous volume of literature on the allelopathy, antimicrobial and insecticidal an $d$ repellent activity of terpenoids ${ }^{5-7}$. Sesquiterpenes like caryophyllene oxide (CPO), widely distributed in medicinal plants such as guava (Psidium guajava), oregano (Origanum vulgare), cinnamon (Cinnamomum spp.), exhibit a wide variety of pharmacological effects, demonstrating antibacterial, antifungal, immunomodulatory, antiinflammatory, antirheumatic, antioxidant and anticancer properties ${ }^{8}$. Moreover, CPO has been shown to inhibit the growth some cancer cells and to induce apoptosis of human prostate and breast cancer cells ${ }^{9}$. Caryophyllene, another important sesquiterpene, is known for its antiinflammatory and local anaesthetic activities ${ }^{10,11}$. It is used in spice blends, citrus flavors, soaps, detergents, creams and lotions and also in a variety of food products and beverages $^{12}$.

Antifungal activity: Evaluation of MIC values of the oils showed a variability of inhibition among all the fungi tested $\left(0.195-25 \mu \mathrm{L} \mathrm{mL}{ }^{-1}\right)$ (Table-2). According to these activity ranks, the essential oils of E. catarium and E. odoratum showed a effective antifungal activity against most of the tested strains, which could be attributed to the high content of the oils, of compounds with known antimicrobial activity, such as caryophyllene, germacrene D and caryophyllene oxide. Fusarium graminearum Schwabe, Rhizoctonia solani AG1-IA, Mucor, Sclerotinia sclerotiorum were more sensitive to the two oils than the other tested strains.

\section{TABLE-2}

ANTIFUNGAL ACTIVITY OF THE ESSENTIAL OIL FROM THE TWO SAMLIES GIVEN AS MIC

\begin{tabular}{lcc}
\hline \multicolumn{1}{c}{ Microorganisms } & \multicolumn{2}{c}{$\begin{array}{c}\text { MIC of samples of } \\
\text { essential oil }\left(\mu \mathrm{L} \mathrm{mL}^{-1}\right)\end{array}$} \\
\cline { 2 - 3 } & E. catarium & E. odoratum \\
\hline Botrytis cinerea & 1.563 & 1.563 \\
Exerohilum turcicum & 12.5 & 6.25 \\
Mucor & $<0.195$ & $<0.195$ \\
Fusarium graminearum & 25 & 25 \\
Sclerotinia sclerotiorum & $<0.195$ & $<0.195$ \\
Rhizoctonia solani AG1-IA & $<0.195$ & $<0.195$ \\
Rhizoctonia solani & 1.563 & 0.783 \\
Fusarium graminearum Schwabe & $<0.195$ & $<0.195$ \\
\hline
\end{tabular}


Previous papers on the antifungal activities of essential oils of some species of various genera have shown that they have varying degrees of growth inhibition effects against some agricultural pathogenic fungal species. The fungistatic properties of the oils are suspected to be associated with the high content of terpenes type components, since there is a relationship between the chemical structures of the most abundant oils and their antimicrobial activities. On the other hand, It is also possible that the minor components might be involved in some type of synergism with the other active compounds. The observed antifungal activity is of importance, because fungi infection have increased considerably, attributed to its intrinsic resistance to commercial fungicides.

In conclusion, the examination of the two oils in this study showed promising prospects for the utilization of natural plant essential oils as a potential source of sustainable eco-friendly botanical fungicides, on the basis of their efficacy on different types of plant pathogens and their low cost and easy availability. However, because the in vitro effects did not always provide a good criterion for their in vivo performances, additional studies are necessary to verify the effectiveness in field conditions.

\section{ACKNOWLEDGEMENTS}

The authors are grateful to Prof. Liping Wang, Analysis and Testing Centre, Jiangnan University, for performing GC-
MS, as well as also grateful to the Microbiology Laboratory, Zhejiang Agriculture and Forestry University for performing microorganism experiment.

\section{REFERENCES}

1. L.C. Tang, N. Wang, X.H. Yang and S.M. Deng, J. Anhui Agric. Sci., 39, 5805 (2011).

2. J.Q. Yuan, J. Feng, J.S. Yang and J.H. Miao, Chinese J. Modern Appl. Pharmacy, 25, 202 (2008).

3. B. Lin, M.X. Zhang, C.H. Kong, X.F. Pang and G.W. Liang, Chinese J. Appl. Ecol., 4, 744 (2003).

4. B. Ling, M.X. Zhang and X.F. Pang, Nat. Prod. Res. Dev., 15, 183 (2003).

5. H. Bouda, L.A. Tapondjou, D.A. Fontem and M.Y.D. Gumedzoe, J. Stored Prod. Res., 37, 103 (2001).

6. E.O. Owusu, J. Stored Prod. Res., 37, 85 (2001).

7. A. Caceres, H. Menéndez, E. Méndez, E. Cohobón, B.E. Samayoa, E. Jauregui, E. Peralta and G. Carrillo, J. Ethanopharmacol., 48, 85 (1995).

8. A. Astani, J. Reichling and P. Schnitzler, Evid. Based Complem. Altern. Med., Article ID 253643 (2011).

9. K.R. Park, D. Nam, H.M. Yun, S.G. Lee, H.J. Jang, G. Sethi, S.K. Cho and K.S. Ahn, Cancer Lett., 312, 178 (2011).

10. Y. Tambe, H. Tsujiuchi, G. Honda, Y. Ikeshiro and S. Tanaka, Planta Med., 62, 469 (1996).

11. C. Ghelardini, N. Galeotti, L. Di Cesare Mannelli, G. Mazzanti and A. Bartolini, Farmaco, 56, 387 (2001).

12. M. Skold, A.-T. Karlberg, M. Matura and A. Borje, Food Chem. Toxicol., 44, 538 (2006). 